\title{
elyra
}

\section{Para uma releitura da relação entre arte e pobreza (a propósito da poética da colagem em Jorge de Lima) ${ }^{1}$}

\author{
Celia Pedrosa \\ Universidade Federal Fluminense (UFF)
}

Resumo: Com o objetivo de rastrear antecedentes modernos da prática contemporânea da arte como ofício múltiplo, serão levantados alguns aspectos concernentes à simultaneidade de poesia e fotomontagem na produção de Jorge de Lima, apontando para uma releitura de sua inscrição modernista e, a partir daí, da relação entre arte e pobreza na história da cultura brasileira.

Palavras-chave: ofício múltiplo, pobreza, fotomontagem

Abstract: In order to find modern antecedents for the contemporary practice of art as a multiple activity, some aspects of the simultaneous production of poems and photomontages by Jorge de Lima will be discussed, pointing to a rereading of his role in Modernism and, ultimately, to the relation between art and poverty in the history of Brazilian culture.

Keywords: multiple craft, poverty, photomontages

1. A literatura brasileira produzida a partir da segunda década do século XX se mostra ao mesmo tempo decepcionante e provocativa no que diz respeito à prática de ofícios artísticos múltiplos. Pois, por um lado, esta parece inexistente nos vários poetas desde então canonizados. Mas essa inexistência pode convidar à discussão das noções mesmas de ofício 
artístico e de sua prática múltipla, retomando importantes inflexões críticas sobre a situação de carência e pobreza de nossa vida cultural.

Ressalte-se, de início, nas primeiras décadas do século $X X$, o importante espaço ocupado pela atividade literária, que usufrui da condição de campo específico, dotado de organização própria e grande força de interferência na vida social, diferentemente do que acontecia com outras práticas artísticas. Os fatores que contribuem para isso têm sido bastante analisados. Como se sabe, ao longo da colonização a palavra oral e escrita teve papel político central, inextricavelmente vinculado a seu uso estético. Foi a importância desse vínculo que inclusive motivou a posterior inclusão no corpus da literatura brasileira de textualidades que desafiam definições convencionais de arte e de gênero, como as cartas de Pero Vaz de Caminha e os sermões do padre Antônio Vieira.

Essa situação se mantém significativa ainda por muito tempo. Já instaurada a luta pela independência, por exemplo, avulta a relação desta com o processo de formação de uma literatura que se queria brasileira, bem como a importância da atuação ao mesmo tempo pedagógica, política e jornalística dos escritores de então. É disso um significativo exemplo a recepção das famosas Cartas Chilenas, atribuídas a Tomás Antônio Gonzaga, cuja inclusão no cânone literário apontava, e antecipadamente, para a necessidade da tão contemporânea discussão seja sobre o caráter problemático da definição do artístico seja sobre o valor de autoria.

Antonio Candido cunhou a imagem da faca de dois gumes para definir essa dupla função da palavra literária, que, se por um lado freou-Ihe a liberdade imaginativa, por outro contribuiu para consolidar sua importância e não deixou de ter efeitos positivos imprevistos (cf. Candido 1987). Duplicidade semelhante ele identifica nos efeitos da situação de pobreza e pouca diferenciação de nossa vida social até meados do século XIX, em virtude da qual continuou cabendo aos escritores a responsabilidade pelo desempenho daqueles múltiplos ofícios não artísticos. Pois justo essa condição de carência e acúmulo de responsabilidades é que, ao mesmo tempo, impulsionou a criação de um gênero discursivo bem singular e produtivo - o ensaio, em que recursos expressivos e metafóricos se aliaram para a análise crítica de nossas características, como exemplifica o trabalho sócio-histórico de Gilberto 
Freyre e Sérgio Buarque de Holanda, que não só deve muito à sua formação como leitores, como a suas atividades de criação e crítica literárias (cf. Candido 1980).

Nos escritores modernistas podemos acompanhar novos desdobramentos dessa situação, na medida em que, com eles, o ensaísmo era do mesmo modo a grande atividade paralela à literatura, servindo à reafirmação de sua hegemonia, mas também à sua articulação aos interesses e problemas de outras práticas artísticas. Esse é o caso, por exemplo, dos estudos de Mário de Andrade reunidos em livros como O baile das quatro artes (1963) e outros vários sobre música popular, além dos avulsos sobre pintura, reunidos posteriormente (cf. Andrade, Mário de: 1974, 1955). E ainda de sua produção epistolar, que mesclava afeto, reflexão e pedagogia, servindo também à aproximação com pintores e músicos como Anita Malfatti, Cândido Portinari ou Camargo Guarnieri, por exemplo.

A importância desses tipos particulares de atividades simultâneas com certeza está na origem de transformações posteriores que desestabilizaram conceitos e métodos da teoria e da crítica literária em nome da necessidade de discutir tradicionais dicotomias entre real e ficcional e abrir espaço para o estudo comparativo de poemas e romances, de um lado, e diários, rascunhos, cartas, crônicas e ensaios, de outro. Quanto a isso, lembremos o valor atribuído, já nos anos 80, à poesia de Ana Cristina Cesar e ao que nela Flora Süssekind chamou de "arte da conversação" e "retórica da correspondência" (cf. Süssekind 1995), ou, atualmente, ao que vem sendo valorizado como hibridismo de poético e ensaístico na escrita de Marília Garcia.

Podemos aproximar esse hibridismo daquele que, na cultura moderna europeia ainda do século XIX, foi praticado por escritores cujo interesse por outras artes, em vez de implicar a dedicação a uma atividade artística simultânea à literatura, motivou, como no caso de Diderot e posteriormente de Baudelaire, semelhante investimento num gênero de escrita ensaística - os salões -, considerado seminal para a crítica de arte, e cuja repercussão se estendeu ainda, por exemplo, às cartas de Rilke sobre Cézanne. ${ }^{2}$ Essa aproximação implica, de fato, uma ampliação do quadro até aqui associado à situação brasileira. Mas também serve para legitimar a compreensão de que a prática artística há muito convida a um comparativismo expansivo, transgressivo de fronteiras de toda ordem. 
Tornada mais incontornável por dados e questões contemporâneas, essa compreensão não deixa de remeter também a outros aspectos especialmente significativos das demandas modernas. Lembre-se a propósito que, sobre vários dos movimentos vanguardistas se disse, a título depreciativo, que apresentaram grandes propostas e manifestos, mas muito poucas obras. Ao reavaliar hoje essa situação de pobreza, o escritor argentino César Aira vai considerar que, tendo percebido a impossibilidade de criação de novas obras-primas, após Balzac e Flaubert - impossibilidade confirmada pelo esforço empreendido por Proust e Joyce para construir um único romance -, os vanguardistas, sabiamente, teriam se dedicado a propor apenas procedimentos, que, desde então, não deixaram de evidenciar sua produtividade, representando simultaneamente um esgotamento e uma possibilidade. ${ }^{3}$

Uma das implicações dessa proposta é que a relação entre diferentes artes, assim como seu exercício simultâneo por um determinado artista, possa e mesmo deva ser considerada, em termos gerais, independente da inscrição de cada uma delas em um campo artístico definido como específico e autônomo, bem como de uma ideia pré-legitimada de arte; e, em termos mais restritos, também de uma concepção específica e autônoma de obra.

2. Sob esse viés, pode-se rever nosso modernismo e nele identificar uma contraditória tessitura de carência e complexidade que contribui para redimensionar alguns consensos críticos relativos à relação interartes. No caso emblemático de Mário de Andrade, por exemplo, já vêm se fazendo estudos que discutem sua desvalorização da fotografia, que considerava mera técnica, e a relacionam a uma preferência conservadora pelas formas tradicionais das artes plásticas - e, nestas, pela sua tradição representativa, com as consequentes dificuldades com o abstracionismo e o surrealismo das vanguardas (cf. Chiarelli 2003: 78-9). Mas, ampliando a avaliação dessa opção do poeta, vem sendo aberto um importante campo de questões através do estudo de sua prática documental, não artística, da fotografia, bem como de suas escolhas pictóricas, como se observa no interessante ensaio de Sérgio Miceli sobre a relação de Mário com os retratos que suscitava e mesmo encomendava aos artistas seus contemporâneos (Miceli: 1996). O mesmo efeito 
pode ser atribuído à crescente atenção a sua epistolografia, inaugurada por Silviano Santiago em estudo que reintroduz o conceito de vida literária - o que lhe permite rever vários aspectos do modernismo, além de contribuir para a flexibilização de fronteiras entre o individual e o coletivo, o confessional e o ficcional, o literário e o não literário. ${ }^{4}$

Abrindo mão da exigência de especificidade e autonomia do ofício artístico, pode-se passar a avaliar dados aparentemente aleatórios, isolados, e por isso considerados pouco significativos, como o fato de Manuel Bandeira ter feito a capa de um livro de Jorge de Lima (Poemas escolhidos, de 1932). Ou de Murilo Mendes ter se dedicado intensamente ao ensaísmo sobre pintura. Ou de Oswald de Andrade ter ilustrado com desenhos seu livro Primeiro caderno do aluno de poesia Oswald de Andrade. E, indo mais adiante, de João Cabral de Melo Neto ter se interessado tanto por Mallarmé quanto pela tipografia - "mera" técnica alçada pelo ilustre antecessor a procedimento fundamental de sua escrita -, conciliando as atividades de poeta, gráfico e editor.

Outra releitura da cena modernista sob essa perspectiva pode ser feita através da produção de Jorge de Lima, que, identificado em nossa tradição como poeta, desenvolveu, com diferentes intensidades, também as atividades de político, médico, romancista, pintor e crítico. Essa escolha tem duplo significado. Por um lado, sua dedicação simultânea à literatura e à pintura, embora representando uma exceção face à tendência mais geral dos escritores modernos, endossa a noção de ofício múltiplo. Por outro lado, sua dedicação pontual e específica à fotomontagem, aqui enfatizada, permite retomar as questões que estamos colocando em torno dessa noção.

Antes de mais nada, pode ser considerado mínimo o interesse que no campo dos estudos literários comparativos, pelo menos no Brasil, tem sido dedicado à fotomontagem. A eles, tal como até recentemente fundamentados, com certeza não servia o caráter assistemático, descontínuo da prática. E também o fato de ela colocar em ação uma proposta de arte impura, na medida em que situada num lugar entre o artesanal e o artístico, o primitivo e o vanguardista. Tensionando, segundo Max Ernst, a autonomia e a especificidade dos campos da pintura e do cinema, a fotomontagem parece manter e mesmo reivindicar apenas uma condição circunstancial de articulação de procedimentos técnicos: a fotografia, a colagem, a montagem. Não por acaso, e indicando um 
deslocamento desses valores, na produção poética brasileira a relação com a pintura, muito forte até os anos 80, vem abrindo cada vez maior espaço para a fotografia e mais recentemente para a fotomontagem. Esse movimento, avaliado em suas contradições por Flora Süssekind (2005), tanto diz respeito a uma repetição epigonal de nossa tradição realista quanto à sua desconstrução - citemos, en passant, neste último caso, nomes mais conhecidos como Nuno Ramos e Cláudia Roquette-Pinto. Do mesmo modo, a noção de montagem vem ocupando lugar cada vez mais significativo no discurso teórico-crítico sobre a literatura, sobre as artes e sua história, na esteira das reflexões sobre a imagem e sobre a visualidade dominantes na cultura contemporânea. ${ }^{5}$

Lembremos então que a montagem foi considerada básica à linguagem do cinema por Eisenstein, que no entanto remete sua origem ao romance de Charles Dickens (cf. Eisenstein 2002). Ela foi também fundamento da prática dadaísta da colagem, por seus próprios produtores remontada à linguagem poética de Rimbaud e Lautréamont. Nesse movimento, então, seu uso se concretiza, provocativa e contraditoriamente, tanto como constitutivo de uma nova forma de arte, o cinema, quanto como motivo de esvaziamento da autonomia e da especificidade de uma outra, neste caso a pintura, bem como de sua reaproximação com a vida, na contracorrente de toda dicotomia simplista entre realismo e experimentalismo. ${ }^{6}$

No caso do uso surrealista da fotomontagem, acrescente-se que, além de implicar a articulação dessas duas técnicas, ele exige o ato de refotografar o já fotografado, produzindo um jogo de proximidade e distanciamento que aumenta a tensão perceptiva e permite ativar o olhar como conjunção disjuntiva do sensível ao construtivo, do imediato ao memorioso, do verossímil ao absurdo, a partir mesmo do uso de recortes de imagens informativas e afetivas, extraídas de jornais, revistas, álbuns, tomadas em sua materialidade mesma. Nesse jogo, a fotomontagem constitui um modo também contraditório de relação com o que seria seu contexto, colocando em questão o próprio significado deste, na medida em que pode ser compreendida tanto como signo e mesmo índice da relação entre arte e ordem industrial, mecânica, de apropriação e reorganização do já existente, quanto como efeito de uma percepção fragmentada e caótica de um mundo e uma cultura esfacelados pela guerra, 
em que se inscrevem heterodoxamente elementos míticos, místicos, oníricos, metafísicos (cf. Rodrigues 1943).

Saúl Yurkievich ressalta como essa conjunção releva de uma temporalidade heterogênea, cuja força se inscreve como contra-atualidade no cerne do progressismo moderno:

Cada collage establece su propria contractualidad comunicativa. Sus rupturas de articulación coexisten sin fundarse unas en otras. Objeto móvil y aleatorio, revela una prodigiosa capacidad de ligazón de conjuntos efímeros, pone en ejercicio uma energía polimorfa que descentra la enunciación y libera a los signos de su inclusión convencional. Pulverizada toda relación de encuadre permanente, los fragmentos son devueltos a una combinatoria completamente abierta. (Yurkievich 1984: 60) ${ }^{7}$

Essa heterogeneidade formal e temporal da fotomontagem pode ser considerada então emblema de uma contemporaneidade expansiva que desorganiza a concepção homogênea de modernidade. Não por acaso, a reavaliação desta, segundo Martin Jay, implica sua percepção como campo de forças várias e a problematização da relação hegemônica estabelecida entre forma e visão clara e unívoca (Jay 2003). Esse mesmo efeito pode ser atribuído ao modo como o trabalho verbal e visual de Jorge de Lima se inscreve no cenário da poesia brasileira moderna, contaminando-o de marcas de contra-atualidade. Justo por isso, seu reconhecimento como grande poeta sempre esteve de par com uma pequena presença nos espaços de legitimação do cânone.

Tal situação deriva, de fato, da dificuldade provocada pela associação de heterogeneidade e irregularidade, consideradas ambas prejudiciais tanto à construção autônoma da forma literária quanto à figuração crítica do nacional. Pois, em sua poesia verbal (dizia ele que todas as suas atividades eram oportunidades de fazer poesia), Jorge se exercitou tanto no verso livre quanto no soneto, tanto no poema curto quanto em longas misturas de meditação e narrativa, tanto na imersão na concretude cotidiana quanto em viagens órficas. Conforme avalia Fábio de Souza Andrade em seu excelente estudo sobre o poeta, se considerada no conjunto sua obra demonstra não ter passado por um amadurecimento linear, como a de Manuel Bandeira do simbolismo para o modernismo; nem se organiza e divide claramente em duas águas, como a de João Cabral de Melo Neto. Ao contrário, dependeria da persistência descontínua de algumas linhas de força que, 
segundo ele, prosseguem subterrâneas e afloram repentinamente em função de encontros felizes - intempestivos, eu diria -, como com o surrealismo.

Embora priorize a análise dos aspectos coesivos da produção especificamente poética e "final" de Jorge, por ele então dividida em fases, Fábio não deixa significativamente de ressaltar a produtividade de uma leitura que viesse a articular, nesse engenheiro noturno, a produção inicial e a tardia, a romanesca e a plástica, em torno da heterogeneidade dos procedimentos de estranheza visual (Andrade, Fábio 1997). Nessa heterogeneidade, podemos ver de fato se manifestar uma fuga "conservadora" dos parâmetros estéticos e ideológicos modernistas - nacionalismo, coloquialismo -, mas, simultaneamente, uma provocante adesão a vanguardismos desconstrucionistas e surrealistas que eles rejeitavam - evidenciando as contradições do próprio movimento.

O mesmo ocorre em sua valorização da técnica "simples" e impura da fotomontagem, em contraposição à maior atenção dada pelos modernistas às artes plásticas já tradicionais, como a pintura e a escultura. Do mesmo modo, observa-se nele a convivência de engajamento moderno e opção religiosa - que somente hoje, em nossos tempos pósutópicos, que obrigam à desconstrução radical da racionalidade moderna, está sendo reavaliada, conforme apontam ainda poucos e recentes estudos, como o de Raul Antelo sobre a relação entre surrealismo, heterodoxia religiosa e heterogeneidade estética no parceiro artístico de Jorge de Lima: Murilo Mendes (Antelo 2006).

Note-se que esse valor de heterogeneidade, heterocronia e polissemia é apontado já desde a recepção modernista das fotomontagens de Jorge de Lima, consideradas por Mário de Andrade, em sua simplicidade técnica, ao mesmo tempo como brincadeira, procedimento ao alcance de qualquer um, vício, oportunidade para revelação de monstros inconscientes recônditos e marco introdutório da arte moderna (Andrade, Mário de 1987). Vale a pena ressaltar que nessa avaliação, em princípio negativa, Mário faz uma enumeração que por si só dá a ver a complexidade contraditória do simples e lúdico em seu valor ao mesmo tempo estético, expressivo e socializante. Do mesmo modo, mas agora sem nenhuma conotação restritiva, Murilo Mendes ressaltava nesse trabalho de Jorge a conjunção de pânico e organização, infância e madureza, ludismo e doença, calma e catástrofe, vida e morte - polos cujo parentesco se descobriria, segundo ele, como quando se folheia um álbum de fotos de 
família; trata-se de um signo, portanto, do ao mesmo tempo próximo e estranho, em sua temporalidade congelada e constelada, perpassada por movimentos e espaçamentos imprevistos da memória, do desejo e da imaginação (Mendes 1943).

Nessa relação entre heterogeneidade e contra-atualidade, interessa aqui enfatizar ainda, quanto aos possíveis efeitos do trabalho de Jorge de Lima com imagens visuais verbais e plásticas - e também quanto à retomada, hoje, da técnica da fotomontagem e do texto-colagem, de que maneira nestes a força de contra-atualidade se manifesta na simultaneidade anacrônica entre modo de produção e modo de leitura. Abertos ao desvio e à portabilidade, nos lembram aqui a Boîte-en-valise, a coleção portátil de Marcel Duchamp, num movimento que, como esse de nossa própria lembrança, implica desconexão com diferentes formas de inscrição originária seja em um campo de linguagem, seja em um campo de espaço-tempo. Quanto a um e a outro, faz sentido lembrar também a imagemmétodo do atlas mnemônico de Aby Warburg, que por isso mesmo tem, contemporaneamente, intensa releitura.

A reunião das fotomontagens de Jorge de Lima em livro, A pintura em pânico, encena de diferentes modos essa cronotopia do deslocamento, do anacronismo, presente nessas imagens do álbum, do atlas, da coleção, da boîte-en-valise. Colocando-as sob a unidade do livro, mas ao mesmo tempo investindo no caráter fragmentário intrínseco à materialidade da página em códex (oposta à continuidade do volumen), a reunião não tem numeradas suas páginas, funcionando assim como campo aberto a inúmeros encadeamentos possíveis, o que é reafirmado na relação arbitrária entre imagens e palavras usadas em seus nomes e/ou legendas. Além disso, o título do livro, publicado em 1943, confirmará a posteriori a íntima relação com a experiência existencial e literária de Murilo Mendes, que lhe escreve a "Nota liminar", e intitulara de A poesia em pânico seu livro de poemas de 1937, num processo que pede para ser visto como o de uma coautoria atribulada, intermitente, que retoma ainda aquela iniciada com a coletânea de poemas Tempo e eternidade, de 1935.

Tais características contribuem para relativizar a relação unívoca entre individualidade, originalidade, autoria e obra que vem sustentando a ideia de arte - afetada já pela prática mesmo da fotografia, da colagem e da fotomontagem. E remetem, também anacronicamente, tanto ao caráter coletivo do trabalho artístico associado a culturas 
primitivas quanto a suas releituras pelo vanguardismo moderno, que tem sido retomado como viés de compreensão da produção artística. A propósito, note-se a importância e a visibilidade readquiridas hoje, quanto à poesia, por coletivos editoriais e poéticos em que o manuseio de técnicas de produção e reprodução gráficas e composição material do livro divide democraticamente espaço e tempo com o trabalho de manipulação de linguagem verbal e visual.

3. Lembrámos aqui inicialmente, quanto à formação da cultura brasileira, a relação entre a pobreza de uma organização social pouco diversificada e a necessidade de exercício simultâneo de várias funções por parte dos intelectuais. Apontámos também que essa simultaneidade se deu no âmbito de atividades ligadas prioritariamente à palavra oral e escrita, aproximando portanto a literatura da política, do jornalismo e da análise históricosociológica, antes que de outras artes. Ressaltámos também a acuidade com que Antonio Candido percebeu como dessa situação de pobreza decorreu contraditoriamente a mobilização de uma forma de escrita híbrida - o ensaio - e, com ela, de uma produtiva prática cujos desdobramentos, desde então, e até hoje, desestabilizam fronteiras entre arte e conhecimento.

Extrapolando os marcos do processo brasileiro e o significado nele adquirido por essa prática, apontámos, quanto à redefinição da relação entre diferentes ofícios artísticos, a articulação entre literatura, pintura e ensaísmo na cultura europeia moderna, bem como o hibridismo fundamental às propostas artísticas de vanguarda. Nestas, ressaltámos a profanação da especificidade de campos artísticos tradicionais, associada à indistinção desierarquizante entre arte e técnica e ao abandono da ideia de criação e obra individuais e originais, em nome do investimento em procedimentos comuns e coletivos. A esse respeito, lembrámos a invasão desconstrutora da visão pictórica pela fotografia e pela colagem, que implicou simultaneamente a problematização da ideia de representação.

Esse vanguardismo, como se sabe, pode ser visto, tanto negativa quanto positivamente, como um desvio anacrônico face à visão evolutiva e racional-progressista de arte e de vida. Pois implicava na valorização de procedimentos simples, precários, associados até então ao primitivo, ao infantil - como fez Mário de Andrade com as fotomontagens de Jorge 
de Lima -, ou mesmo, em polo oposto, à senilidade e à doença, como também se fez a propósito das crises psicológicas do poeta. Assim pode ser igualmente compreendido, por exemplo, as transformações no trabalho plástico de Matisse, em que o empenho experimental da juventude, precarizado por essas dificuldades tardias, se desdobra na prática do "desenho com tesoura" - que representa um retorno diferido, anacrônico, e por isso provocativo, à colagem de origem cubista.

Mas desde muito antes, a gagueira lúdica já reivindicada no nome autoatribuído pelo movimento dada performava essa articulação de carência e força de contra-atualidade das vanguardas - que, no entanto, não impediu sua posterior transformação em obra, monumento, de novo submetida a uma concepção aurática de arte. Trata-se aqui, então, de pensar a produtividade atual do resgate dessa força contraditória de pobreza e anacronismo. Em relação ao diálogo entre vanguardas europeias e cultura brasileira após o modernismo, essa tarefa foi empreendida de modo seminal e brilhante por Gilda de Mello e Souza, em ensaio dedicado a Jean Maugüé, Claude Lévi-Strauss e Roger Bastide, que aqui vieram atuar como professores na Universidade de São Paulo, nas décadas de 1930 e 1940 justo quando se consolidava o cânone modernista e Jorge de Lima articulava atividade poética e pictórica (Souza 1980).

Nos textos sobre pintura aqui escritos por eles, Gilda percebe duas tendências opostas. A primeira, característica do filósofo Maugüé, e mais tarde adotada por LéviStrauss, é vista como de louvação de uma "estética da representatividade, extremamente racional, europeia - diria mesmo, de uma estética do Classicismo" (idem: 16-17). A segunda, adotada também por Lévi-Strauss apenas quando ainda jovem, e direcionadora de toda a reflexão de Roger Bastide, é por ela definida pela integração de interesse antropológico e estética de vanguarda, alimentada pela influência do dadaísmo e do surrealismo. Em decorrência disso, relevava os valores canônicos de obra de arte e de obra-prima e atentava para o potencial de formas e procedimentos comuns em que se miscigenavam o artesanal e o místico, o primitivismo e a tradição erudita.

As questões propostas por esse texto de Gilda podem ser vistas como um instigante prenúncio daquelas que Haroldo de Campos apresenta no ensaio intitulado justamente "Arte pobre, tempo de pobreza, poesia menos", escrito dez anos depois. ${ }^{8}$ Nele, o termo 
"arte pobre" - também referido às artes plásticas, mas ao movimento italiano da década de 1960 - vai servir para enfatizar a importância em nossa literatura de uma genealogia em que a relação entre experiência literária e social se coloca através da opção por uma estética gaga, que profana tanto a retórica realista quanto a romântica em sua crença na plenitude representativa ou expressiva do literário. Usada pela primeira vez pelos cultores do realismo oitocentista para ridicularizar o caráter lacunar, intermitente da linguagem de Machado de Assis, a gagueira é retomada por Haroldo, agora como atributo positivo, e associada, na esteira do paradigma vanguardista, à metonímia cubista, à visão tateante, à construção em mosaico e caleidoscópio. E identificada, de diferentes modos, nas obras de Oswald de Andrade, Graciliano Ramos, João Cabral de Melo Neto e Augusto de Campos.

A possibilidade de aproximação desses dois ensaístas em princípio pertencentes a campos críticos não só divergentes mas frequentemente antagônicos evidencia a potencialidade da discussão em torno da noção de pobreza estética. ${ }^{9}$ Não vamos explorar aqui a comparação entre ambos em todo seu alcance. Para efeito da leitura que estamos encaminhando, ainda que de modo superficial, interessa ressaltar, para além da semelhança já apontada, uma diferença em especial. No ensaio de Haroldo de Campos, a noção de pobreza estética é associada a magreza, a síntese, e utilizada para valorizar uma tendência discursiva predominantemente racional-construtiva e muito especificamente literária.

Já o ensaio de Gilda, bem ao contrário, mobiliza essa noção para valorizar a partir de Roger Bastide uma estética que não se preocupa com a hierarquia entre artístico e não artístico nem prioriza uma concepção racional-construtiva. Por isso, vai atribuir grande relevância ao barroco - estilo que não tem lugar na estética magra então proposta por Haroldo, embora, como se sabe, vá receber atenção especial em outros momentos de sua reflexão. Observado na arquitetura e escultura brasileiras, vai servir à valorização de uma estética pobre porque mestiça de artístico e místico assim como de linhas retas e curvas, de elaboração rococó e uso de materiais não nobres como a madeira e a pedra-sabão.

O reconhecimento da existência dessas duas formas tão distintas de definir uma estética da pobreza na literatura e na cultura brasileiras problematiza o discurso crítico hegemônico a partir de nosso modernismo. Bem representado pela perspectiva de Haroldo de Campos, ele conceberia a articulação de experimentalismo de vanguarda e inscrição 
social periférica de modo a associar recorte, fragmentação e síntese. A releitura dessa articulação pelo viés retomado por Gilda nos faz remontar a outros efeitos estéticos de vanguarda que, desdobrando-se desde Rimbaud, se manifesta numa composição híbrida de delírio e artesanato, misticismo e percepção, de que as fotomontagens surrealistas, e nelas a técnica do corte e do recorte, são o maior exemplo.

Nesse sentido, podemos compreender também a relação entre poesia, visualidade e fotomontagem em Jorge de Lima, e o modo como nela se articulam anacronismo e vanguardismo, percebendo na irregularidade, na diversidade, na intermitência de sua atividade, um empobrecimento face ao ideal canônico de arte e literatura, em que se manifestam a potência do híbrido e do excesso.

Não por acaso a leitura de sua poesia, bem como a de seus quadros, solicita a recuperação de procedimentos como os do surrealismo e do barroco, em que o excesso, na contracorrente das retóricas da plenitude, produz um jogo irresolvido entre presença e ausência, imagem e vazio. Tal recuperação pode ser fundamental na avaliação de tendências da poesia contemporânea em que se assiste ao retorno do poema longo e do verso discursivo, assim como do reinvestimento na primeira pessoa, transtornados por procedimentos diversos de corte, colagem e heterogeneização. 


\section{Bibliografia}

Aira, César (2007), "A nova escritura", in Pequeno manual de procedimentos, Curitiba, Editora Arte e Letra.

Andrade, Fábio de Souza (1997), O engenheiro noturno: a lírica final de Jorge de Lima, São Paulo, EdUSP.

Andrade, Mário de (1974), Aspectos da literatura brasileira, São Paulo, Martins.

-- (1987), "Fantasias de um Poeta", in Paulino, Ana Maria (org.), O Poeta Insólito Fotomontagens de Jorge de Lima, São Paulo, IEB/USP.

-- (1963), O baile das quatro artes, São Paulo, Martins.

-- (1955), O empalhador de passarinho, São Paulo, Martins.

Antelo, Raul (2006), "Murilo Mendes, o surrealismo e a religião", in Boletim de Pesquisa NELIC, v. 6, n. 8/9 - Poesia: passagens e impasses.

Bürger, Peter (2012), Teoria da vanguarda, São Paulo, CosacNaify.

Campos, Haroldo de (1992), Metalinguagem \& outras metas, São Paulo, Perspectiva.

Candido, Antonio (1987), "Literatura de dois gumes", in A educação pela noite e outros ensaios, São Paulo, Ática.

-- (1980), "Literatura e cultura de 1900 a 1945", in Literatura e sociedade, São Paulo, Cia. Editora Nacional.

Chiarelli, Tadeu (2003), “A fotomontagem como 'Introdução à Arte Moderna': Visões Modernistas sobre a Fotografia e o Surrealismo", in ARS - Revista do Departamento de Artes Plásticas (ECA/ USP), São Paulo, p.78-79.

Chklovski, V. (1971), "A arte como procedimento", in Toledo, Dionísio (org. e apresentação), Teoria da literatura. Formalistas russos, Porto Alegre, Globo.

Deleuze, Gilles (1997), “Ga-gue-jou”, in Crítica e clínica, São Paulo, Editora 34.

-- (2006), "Louis Wolfson, ou o procedimento", in Crítica e clínica, São Paulo, Editora 34. 
Didi-Huberman, Georges (2006), Ante el tiempo. História del arte y anacronismo de las imagénes, Buenos Aires, Adriana Hidalgo.

Eisenstein, Serguei (2002), “Dickens, Griffith e nós", in A forma do filme, Rio de Janeiro, Zahar.

Jay, Martin (2003), "El modernismo y el abandono de la forma", in Campos de fuerza. Entre la historia intelectual y la crítica cultural, Buenos Aires, Paidós.

Kempinska, Olga (2011), Mallarmé e Cézanne: obras em crise, Rio de Janeiro, NAU/FAPERJ.

Mendes, Murilo (1943), "Nota liminar", in Lima, Jorge de, A pintura em pânico, Rio de Janeiro, Tipografia Luso-Brasileira.

Miceli, Sérgio (1996), Imagens negociadas: retratos da elite brasileira (1920-1940), São Paulo, Companhia das Letras.

Perloff, Marjorie (2013), "Da vanguarda ao digital. O legado da poesia concreta brasileira", in O gênio não-original, Belo Horizonte, EdUFMG.

Pic, Muriel (2015), As desordens da biblioteca, Belo Horizonte, Ed. Relicário.

Rodrigues, Simone (1943), "Introdução", in Lima, Jorge de. A pintura em pânico. Fotomontagens, Rio de Janeiro, Caixa Econômica Federal.

Santiago, Silviano (1989), "O intelectual modernista revisitado", in Nas malhas da letra, São Paulo, Cia. das Letras.

Souza, Gilda de Mello e (1980), "A Estética rica e a Estética pobre dos professores franceses", in Exercícios de leitura, São Paulo, Duas Cidades.

Süssekind, Flora (1995), Até segunda ordem não me risque nada. Os cadernos, rascunhos e a poesia-em-vozes de Ana Cristina César, Rio de Janeiro, 7Letras.

-- (2005), “Desterritorialização e forma literária. Literatura brasileira contemporânea e experiência urbana", in Revista Literatura e sociedade, USP, Departamento de Teoria Literária e Literatura Comparada, no 8. 
Celia Pedrosa é pesquisadora 1-C do CNPq e professora de Teoria da Literatura e Literatura Comparada no Programa de PG em Estudos de Literatura na Universidade Federal Fluminense. Coordena os grupos de Pesquisa "Poesia e contemporaneidade", com a Prof. Ida Alves, e "Pensamento teórico-crítico sobre o contemporâneo", com a Prof. Diana Klinger. É membro do Conselho Editorial das Revistas Gragoatá (UFF), Escritos (FCRB), Outra travessia (UFSC), Cadernos de Literatura Comparada (Universidade do Porto - Portugal). Publicou os livros Antonio Candido: a palavra empenhada (EdUSP/EdUFF,1994), Ensaios sobre crítica e contemporaneidade (EdUFF, 2011), e, como organizadora, entre outras, as coletâneas Poéticas do olhar (7 Letras, 2004) e Poesia e contemporaneidade (Argos, 2001), com Maria Lucia Camargo; e Subjetividades em devir (7 Letras, 2008) e Sobre poesia: outras vozes (7 Letras, 2016), com Ida Alves.

\section{NOTAS}

\footnotetext{
${ }^{1}$ Este texto foi concebido para apresentação no Colóquio Ofício Múltiplo: Poetas em Outras Artes, realizado na Universidade do Porto em outubro de 2015, com o objetivo de investigar antecedentes modernos da prática de ofícios múltiplos por artistas contemporâneos.

${ }^{2}$ Cf. a interessante recuperação desse diálogo por Olga Kempinska (2011) em Mallarmé e Cézanne: obras em crise, Rio de Janeiro, NAU/FAPERJ.

${ }^{3}$ Cf. Aira, César (2007), "A nova escritura”, in Pequeno manual de procedimentos, Curitiba, Editora Arte e Letra. Os efeitos desconstrutivos dessa noção podem ser encontrados também na relação entre escrita, uso da língua e esquizofrenia apontada em: Deleuze, Gilles (2006), "Louis Wolfson, ou o procedimento", in Crítica e clínica, São Paulo, Editora 34.

${ }^{4}$ Cf. "O intelectual modernista revisitado", in Nas malhas da letra, São Paulo, Cia. das Letras, 1989.

5 Interessante a esse propósito é a recente publicação de As desordens da biblioteca, de Muriel Pic (Ed. Relicário, 2015), que combina fotomontagens, análise de fotografias e uso destas para analisar a biblioteca como modo de organização. Antes dela, tem se constituído em referência fundamental a reflexão de Georges Didi-Huberman sobre a imagem, especialmente, nesse caso, em Ante el tiempo. História del arte y anacronismo de las imagénes, Buenos Aires, Adriana Hidalgo, 2006.
}

${ }^{6}$ Cf. a avaliação feita a esse propósito por Peter Bürger, em Teoria da vanguarda, São Paulo, Cosac Naify, 2012. 
${ }^{7} \mathrm{~A}$ esse respeito nos forneceu subsidio fundamental a tese de doutorado de Bárbara Nayla Piñeiro de Castro Pessôa, intitulada Caminhos da recepção surrealista no Brasil e Na Argentina. Criação e crítica em Murilo Mendes e Julio Cortázar, orientada pela professora Viviana Gladys Gelado. Niterói: Universidade Federal Fluminense/Programa de PG em Literatura Comparada, 2015.

${ }^{8} \mathrm{O}$ texto teve pelo menos duas publicações em periódicos antes de ser incluído em edição da coletânea de Campos, Haroldo de (1992), Metalinguagem \& outras metas, São Paulo, Perspectiva.

${ }^{9}$ Não se pode deixar de lembrar aqui a reflexão sobre a gagueira discursiva proposta por Gilles Deleuze em “Ga-gue-jou”, in: Deleuze, Gilles (1997), Crítica e clínica, São Paulo, Editora 34. Também interessante, sob outro ângulo, é a análise de Marjorie Perloff sobre a relação entre vanguardismo e condição periférica, em "Da vanguarda ao digital. O legado da poesia concreta brasileira", in: Perloff, Marjorie (2013), O gênio não-original, Belo Horizonte, EdUFMG. 